\title{
O RISCO DA CORRUPÇÃO NA ARBITRAGEM: UMA VISÃO DA METODOLOGIA INTERNACIONAL DAS RED-FLAGS DIANTE DAS TENDÊNCIAS E APLICAÇÕES DA LEGISLAÇÃO BRASILEIRA
}

\author{
THE RISK OF CORRUPTION IN ARBITRATION: A VIEW OF THE INTERNATIONAL \\ METHODOLOGY OF RED-FLAGS IN FRONT OF TENDENCIES AND APPLICATIONS OF \\ BRAZILIAN LEGISLATION
}

\section{Theresa Christine de Albuquerque Nóbrega}

\begin{abstract}
Mestre e Doutora em Direito Público Público pela Universidade Federal de Pernambuco. Pós-doutoranda pela Externado de Bogotá. Professora de Direito Administrativo da Universidade Católica de Pernambuco. Professora da Especialização em Direito Administrativo da Universidade Federal de Pernambuco - UFPE. Presidente da Subcomissão de Direito do Terceiro Setor da OAB-PE. Advogada. E-mail: theresanobregaadv3setor@gmail.com
\end{abstract}

\begin{abstract}
Alberto Jonathas Maia de Lima
Doutorando em Direito com ênfase em Arbitragem Internacional pela Universidade Federal de Pernambuco. Mestre em Direito Processual pela Universidade Católica de Pernambuco. Graduado em Direito pela Universidade Católica de Pernambuco. Estudou Arbitration of International Law na Universiteit Leiden. Membro da Lista de árbitros da Câmara de Arbitragem Especializada CAMES e da CMAA ACIF. Fundador do Grupo Marco Maciel de Mediação e Arbitragem (GMMA) da Universidade Católica de Pernambuco. Colaborador do Grupo de Estudos em Direito

Administrativo CNPq/UNICAP. Membro da Comissão de Conciliação, Mediação e Arbitragem da OAB/PE, da Associação Brasileira de Direito Processual - ABDPro e da Associação Brasileira dos Estudantes de Arbitragem ? ABEArb e da Iniciativa de Novos Arbitralistas da INOVARB-AMCHAM. Professor da Universidade Maurício de Nassau. Professor convidado da Universidade Católica de Pernambuco. Advogado em Recife. E-mail: alberto_maia_lima@hotmail.com
\end{abstract}

Recebido em: 17/03/2020

Aprovado em: 13/11/2020

RESUMO: O presente artigo tem por objetivo analisar como a corrupção pode ser analisada nos processos arbitrais. Com a ampliação da utilização da arbitragem envolvendo a Administração Pública é necessária uma reflexão sobre o tratamento da corrupção por entidades e julgadores privados. A prática internacional oferece algumas diretrizes e casos julgados que podem nortear possíveis soluções. Diante desse novo cenário, será possível traçar pelo menos três posições para o tratamento da corrupção na arbitragem e também encontrar na legislação nacional algumas soluções jurídicas para essa problemática. Para tanto, será utilizada metodologia de revisão teóricobibliográfica de autores nacionais e estrangeiros que abordam direta ou indiretamente o assunto. $\mathrm{O}$ procedimento metodológico utilizado será o dedutivo, partindo-se da análise macroanalítica dos institutos do Corrupção a Arbitragem, aplicando-os na especificidade do assunto.

Palavras-chave: Administração Pública; Arbitragem; Corrupção; Publicidade.

ABSTRACT: This article aims to analyze how corruption can be analyzed in arbitration Revista de Direito Brasileira | Florianópolis, SC | v. 27 | n. 10 | p.241-261 | Set./Dez. 2020 
proceedings. With the expansion of the use of arbitration involving the Public Administration, it is necessary to reflect on the treatment of corruption by private entities and judges. International practice offers some guidelines and judged cases that can guide possible solutions. Given this new scenario, it will be possible to draw at least three positions for the treatment of corruption in arbitration and also find in national legislation some legal solutions to this problem. To do so, the theoretical-bibliographic review methodology of national and foreign authors who address the subject directly or indirectly will be used. The methodological procedure used will be the deductive one, starting from the macroanalytical analysis of the institutes of Corruption and Arbitration, applying them in the specificity of the subject.

Keywords: Public Administration; Arbitration; Corruption; Publicity.

SUMÁRIO: Introdução; 1 A corrupção no contexto da prática arbitral; 2 A prática internacional: O uso da metodologia Red Flags; 3 Casos de corrupção analisados por cortes arbitrais; 3.1 Caso World Duty Free v. Quênia.; 3.2 Caso CCI n. 6497; 3.3 Caso CCI n.1100; 3.4 Caso CCI n.13914; 4 A tendências no âmbito nacional; 5 Aplicações específicas com base no direito brasileiro.; $5.1 \mathrm{~A}$ verificação pelos árbitros da ocorrência de um tipo penal praticado pelas partes; 5.2 A corrupção praticada pelo árbitro; 5.3. A corrupção no momento da pactuação da cláusula compromissória.; Considerações finais; Referências.

\section{INTRODUÇÃO}

O Brasil é um país com elevados indicares de judicialização no que tange aos conflitos de interesse decorrentes de relações contratuais e extracontratuais no âmbito de relações de direito público e de direito privado, com muitas demandas potencializadas no âmbito da fazenda pública em função da ineficiência do Estado, parâmetros precários de segurança jurídica no trato do setor privado e regulação inadequada, considerando matrizes regulatórias de organismos internacionais como a ONU e a OCDE (CNJ, 2020). ${ }^{1}$

Nesse contexto, a noção de acesso à justiça vinculada ao ingresso de ação judicial, que se acomoda no inconsciente coletivo da sociedade como parâmetro de racionalidade voltada ao encontro da equidade, vive um tempo de desconstrução dos elementos mitológicos de um passado já esvaziado de toda a glória simbólica conduzida na espada, na balança e, sobretudo, na toga (GRINOVER, 2018).

Trata-se de um processo cultural lento mas gradativamente promissor que decorre de um movimento de decidibilidade de conflitos baseado na noção de justiça multiportas (NALINI, 2016), onde o Poder Judiciário continua mantendo seu status jurisdicional, mas perde a exclusividade diante de manifestações de justiça que estimulam a consensualidade dos conflitos numa avenida que permite aos demandantes passearem por esquinas paralelas aos gabinetes judiciais, onde há outros escritórios com métodos distintos para a administração das contendas.

A arbitragem é um desses caminhos, se caracterizando como mecanismo privado de solução de disputas em que pessoas físicas e jurídicas, nacionais e estrangeiras, privadas ou públicas poderão resolver seus conflitos relativos a direitos patrimoniais disponíveis através de uma decisão definitiva do árbitro.

Conforme interpretação sistemática da Lei 9.307/1996 que dispõe sobre arbitragem, o instituto pode ser definido como técnica extrajudicial de resolução de conflitos pelo qual pessoas capazes contratam um terceiro para decidir seus conflitos relativos a direitos patrimoniais disponíveis (GRINOVER, 2003).

\footnotetext{
${ }^{1}$ De acordo com o CNJ, o estoque de processos pendentes ao final de 2018, em todos os órgãos do Poder Judiciário, foi de 78.691 .031 ações.
} 
A priori, a arbitragem pode ter oferecido um formato de composição de conflitos com traços mais estimulantes para os conflitos privados, mas a publicização das ferramentas de composição extrajudicial avança junto à administração, não só em função da abertura dos marcos regulatórios de mediação e arbitragem específicos para relações de conflito polarizadas pela potestade, mas também em função do esforço realizado pelo Estado para equipar as câmaras.

O cenário que apresenta a consensualidade administrativa como tendência impõe a reflexão sobre o avanço da arbitragem diante do risco indicado pelo inimigo número um da boa gestão pública, qual seja, a corrupção.

No contexto desse estudo, entendemos a corrução como aquele padrão de comportamento que se afasta das normas predominantes no sentido político institucional, isto é, centradas no interesse público. Conforme acentua Zani Andrade Brei (1996), esse comportamento desviante se associa a uma particular motivação - o ganho particular a em prejuízo do público -, e afirma: "no ato corrupto existe sempre ganho para o corruptor e o corrupto e perda para outros, especialmente o público". Realmente, praticada por particulares, gestores públicos ou árbitros a corrupção gera abusos, violações e prejuízos ao interesse público.

Nesse contexto nosso estudo abordará aspectos relacionados a corrupção no contexto arbitral e o uso da metodologia das red-flags ${ }^{2}$ enquanto indicadores de possíveis condutas corruptas bastante utilizadas no cenário internacional. Avançando, traremos alguns casos envolvendo corrupção analisados por cortes arbitrais e seus diferentes desfechos e posteriormente analisaremos as possíveis soluções que a legislação nacional pode dar para casos de corrupção representadas por três possíveis correntes e, para concluir e demonstrar a relevância do tema, apontaremos possíveis soluções para algumas problemáticas que podem vir a ser enfrentadas pela prática arbitral.

Para tanto, foi utilizada metodologia de revisão teórico-bibliográfica de autores nacionais e estrangeiros que abordam direta ou indiretamente o assunto. $\mathrm{O}$ procedimento metodológico utilizado foi o dedutivo, partindo-se da análise macroanalítica dos institutos do Corrupção a Arbitragem, aplicando-os na especificidade do assunto.

\section{A CORRUPÇÃO NO CONTEXTO DA PRÁTICA ARBITRAL}

A corrupção é um fenômeno arraigado à Administração Pública de todos os tempos e de todas as modelagens de gestão, mesmo depois da introdução de sistemas racionais de ordenação de poder trazidos pela reforma burocrática e pela reforma gerencial nos Estados de matriz ocidental no século XX (DIAS, 2003). ${ }^{3}$

No que tange a corrupção na Administração Pública, é fundamental partimos da premissa de que apesar de sua interface endógena (no âmbito interno das corporações públicas) não se vincular apenas as relações externas da gestão pública pois, é na interface exógena, que compreende as relações do Estado com parceiros, fornecedores, autorizatárias, permissionárias e concessionárias de bens e serviços que o risco de captura se pontencializa de forma mais expressiva (ROSE-RCKEMAN; ALIFKA, 2019, p. 125-157).

O tema espinhoso a ser abordado nesse estudo, é o tratamento da corrupção na arbitragem. $\mathrm{Na}$ realidade, embora não haja grande análise de trabalhos doutrinários sobre o tema, são

\footnotetext{
${ }^{2}$ O termo red-flag é utilizado por Lorenzo Parodi (2005) em tradução livre significa bandeira vermelha, isto é, indicador suspeito. Segundo o autor com a utilização de red-flags torna-se possível identificar, prevenir e perceber a existência de um ambiente corrupto, fraudulento ou a prática de ilícitos.

${ }^{3}$ Maria Tereza Fonseca Dias faz um estudo pormenorizado dos marcos brasileiro de ruptura e pós-ruptura do patrimonialismo, evidenciando no final dos anos 1930 a criação do DASP como eixo para a burocratização da Administração Pública brasileira, passando pela tentativa de redesenho do modelo burocrático com o Decreto-Lei 200/1967 e elucidando o argumento de contraponto da reforma gerencial, que utilizou instrumentos de retórica para desconstruir o valor da burocracia mas trouxe consigo três modelos de reordenação da burocracia com parâmetros de eficiência para o núcleo estratégico do governo federal e a proposta de reposicionamento da administração indireta com a introdução das agências executivas e reguladoras..
} 
quantitativa e qualitativamente relevantes os julgamentos arbitrais e artigos abordando o assunto, o que já viabiliza o reconhecimento de balizas importantes para o estudo do tema no âmbito do direito administrativo e do direito arbitral.

De acordo com a análise da transparência internacional, o Brasil ocupa atualmente a $106^{\mathrm{a}}$ colocação entre 180 países avaliados num índice que indica o nível percebido de corrupção no setor público (Transparência Internacional, 2019). Essa colocação contrasta com o fato do Brasil ser considerado o $3^{\circ}$ país com mais partes envolvidas em arbitragem (VIVIANI, 2020).

A aproximação cada vez maior entre o público e o privado torna o patrimônio público vulnerável à apropriação de indivíduos ou grupos de indivíduos organizados para satisfazer seus próprios interesses. Essa tendência é vislumbrada por Celso de Melo na referência a distorção de uma conexão inerente a atuação do Poder Público, que se consubstancia em "sinal de degradação da própria dignidade da atividade política" e atua "em favor de pretensões inconfessáveis e lesivas aos valores ético-jurídicos que devem conformar, sempre, a atividade do Estado"4.

Os impactos econômicos são lamentáveis com o aumento dos valores dos contratos celebrados pela Administração Pública, com a inclusão do "custo propina", pagamento de "comissões" e o direcionamento dos recursos públicos em detrimento do interesse público, levando os economistas a afirmarem que o custo da corrupção tem efeitos inclusive na redução de investimentos estrangeiros (FORTINI; MOTTA, 2016, p. 94).

A corrupção é uma das formas de apropriação privada da coisa pública que viola, entre outros, os princípios da moralidade administrativa, da impessoalidade, da confiabilidade, da prestação de contas e responsabilidade e da transparência (ZIMMER, 2018) ${ }^{5}$. Por este motivo, o combate à corrupção se determina como uma das chaves principais de defesa do interesse público e "demanda cuidados que se entrelaçam numa incessante tentativa de evitar desvios comportamentais e incentivar a adoção de práticas que possam minimizar os riscos de sua ocorrência"(FORTINI; MOTTA, 2016, p. 111).

Como fenômeno inerente à Administração Pública, a corrupção não é manifestação passível de ser expurgada do Estado, tampouco seria possível definir indicadores precisos, como aqueles que mensuram o desemprego ou a inflação, para tentar definir um teto tolerável de inatividade (PUENTES, 2002, p.903-975) no seu controle, mas a falta de um protocolo racional de

\footnotetext{
4 “A corrupção impregnou-se, profundamente, no tecido e na intimidade de algumas agremiações partidárias e das instituições estatais, contaminando o aparelho de Estado, transformando-se em método de ação governamental e caracterizando-se como conduta administrativa endêmica, em claro (e preocupante) sinal de degradação da própria dignidade da atividade política, reduzida por esses agentes criminosos ao plano subalterno da delinquência institucional" AP 996, Relator(a): Min. EDSON FACHIN, Segunda Turma, julgado em 29/05/2018,

${ }^{5}$ A transparência internacional adota o seguinte entendimento: Em termos gerais, a corrupção é o abuso de poder confiado a alguém para obtenção de ganho privado. Pode ser classificada como grande corrupção, pequena corrupção e aquelas de natureza política ou privada (também conhecida como "corrupção comercial") a depender do volume de recursos apropriados indevidamente e do setor em que ocorre. A grande corrupção corresponde a atos ilícitos praticados pelo alto escalão de governos, que distorcem políticas públicas e o funcionamento dos estados, permitindo que líderes se beneficiem a despeito do interesse público, e também por empresários e executivos de grandes empresas privadas, com prejuízos para a eficiência da economia e ampliação das desigualdades sociais. A pequena corrupção se refere ao abuso cotidiano cometido por servidores públicos locais de baixo e médio escalão em suas interações com pessoas comuns. Neste caso, muito frequentemente esses cidadãos tentam acessar bens e serviços públicos como hospitais, escolas, delegacias de polícia e outras agências, mas só o conseguem mediante pagamento de determinada quantia a um funcionário público. A corrupção política se revela na manipulação de políticas públicas, interferência nas instituições e mudanças de regras na alocação de recursos e em linhas de financiamento por parte de autoridades, que abusam de sua posição para ganhar poder, status e dinheiro. A corrupção privada ou comercial é aquela que não envolve o Poder Público, mas entes privados apenas. Ocorre, por exemplo, quando um funcionário do setor de compras de uma empresa privada recebe suborno para favorecer algum fornecedor também privado. Normalmente, ocorre sem o conhecimento dos superiores hierárquicos e pode resultar em grandes prejuízos às empresas, aos seus sócios controladores e minoritários, além de gerar distorções ao próprio funcionamento do mercado. Apesar disto, ela ainda não é tipificada como crime em alguns países, entre eles (até o momento da redação deste texto em maio de 2018) o Brasil. Disponível em https://transparenciainternacional.org.br/quem-somos/perguntas-frequentes/
} 
observação e contenção do fenômeno não justifica o arrefecimento de políticas públicas de enfrentamento constante dos movimentos de deturpação do interesse público (NIETO, 2013) ${ }^{6}$.

As contratações públicas têm sido o principal ambiente de corrupção e malversação do dinheiro público. Ao longo das últimas décadas, agentes públicos e privados utilizaram-se dessas contratações para desviar os recursos do erário seja para seu ganho próprio, seja para financiar campanhas eleitorais desde sempre, mas comunicação social edificou a construção de uma lista de escândalos mais emblemáticos, agregando cifras, metodologias, parcerias e entes públicos sobressaídos (HERMES, 2020).

\begin{tabular}{|l|l|}
\hline \multicolumn{1}{|c|}{ Escândalo } & \multicolumn{1}{c|}{ Valor desviado } \\
\hline Operação Lava Jato & $\mathbf{R} \$ 42,8$ bilhões \\
\hline Banestado & US\$30 bilhões \\
\hline Zelotes & $\mathbf{R} \$ 19$ bilhões \\
\hline Vampiros da Saúde & $\mathbf{R} \$ 4,08$ bilhões \\
\hline Banco Marka & $\mathbf{R} \$ 3,7$ bilhões \\
\hline Fundos de Pensão & $\mathbf{R} \$ 3$ bilhões \\
\hline Jorgina de Freitas & $\mathbf{R} \$ 2$ bilhões \\
\hline Juiz "Lalau" e o TRT & $\mathbf{R} \$ 2$ bilhões \\
\hline Navalha na Carne & $\mathbf{R} \$ 1,06$ bilhões \\
\hline Anões do Orçamento & $\mathbf{R} \$ 800$ milhões \\
\hline
\end{tabular}

Fonte: Os dez maiores casos de corrupção na história do Brasil. Disponível em: https://spotniks.com/os-10-maiorescasos-de-corrupcao-da-historia-do-brasil/. Acesso em 27 de janeiro de 2020.

De acordo com as Nações Unidas (ONU) o Brasil tem gasto, em média, duzentos bilhões de reais por ano com a corrupção, sendo a operação Lava-Jato um tipo de divisor d'águas na percepção da sociedade e das instituições acerca dos valores e metodologias empregadas nas fraudes em desfavor do dinheiro público (NIETO, 2013).

Um dos impactos esperados da operação lava Jato é a revisão da modelagem utilizada nas contratações públicas, pois os Tribunais de Contas e Agências de Regulação têm se tornado cada vez mais exigentes na averiguação dos contratos públicos para aquisição de insumos, prestação de serviço, obras e concessões, incluindo as parcerias público-privadas (ABREU, 2020).

As Cortes Superiores no Judiciário estão cada vez mais incitadas pela comoção popular, vivendo do reality show do direito administrativo do espetáculo (JUSTEN FILHO, 2017), o que indica o enfrentamento cotidiano da opinião pública numa atmosfera em que o combate a corrupção parece se perpetuar numa agenda de ruptura para o Brasil diante das suas organizações e perante a comunidade internacional.

Nesse contexto, é necessário observar que a política anticorrupção que tem sido desenvolvida delineada no âmbito da Administração Pública apresenta vários frontes, considerando aspectos da governança junto as relações entre Poder Público e recursos humanos e entidades privadas em diversos níveis de contratualização que alcançam desde os fornecedores dos insumos cotidianos até as concessões de alta complexidade no âmbito das parcerias público privadas.

Os pontos concernentes à contratualidade administrativa abarcam níveis expressivos de conflito que as leis 8.987/1995,11079/2004 e 13.303/2016 já consideraram amenizar com padrões de consensualidade administrativa. Dessa forma, a arbitragem já está na agenda dos instrumentos de resolução de disputas nas permissões e concessões comuns, bem como nas parcerias públicoprivadas e na rotina das empresas estatais.

\footnotetext{
${ }^{6}$ Em pesquisa realizada sobre a corrupção na Espanha durante um lapso de vinte anos, Alejandro Nieto refere a corrupção como fenômeno inerente a Administração Pública e elucida a necessidade de que os Estados implementem políticas públicas para amenizar as práticas que desviam dinheiro do erário público.
} 
Essa tendência é afirmada no projeto de lei 1292/92/1995 que propõe a ruptura da Lei 8.666/1993, ajustando as contratações públicas no âmbito de todas as entidades federativas e nas entidades da administração indireta de natureza não empresarial.

Em âmbito internacional, a maioria dos contratos comerciais internacionais possuem cláusulas compromissórias arbitrais. Diante disso, existem válidas preocupações de que as partes dos contratos negociados de forma ilícita possam fazer da arbitragem um ambiente ideal de corrupção: primeiro porque o procedimento é confidencial e em segundo lugar porque os árbitros são tradicionalmente relutantes em investigar atos criminalmente ilícitos por sua própria iniciativa. O resultado é preocupante: cria-se um risco real de que a corrupção possa ser legitimada e convalidada por meio de processos arbitrais (CAVE, 2019).

Nesse contexto é possível prever que durante uma arbitragem envolvendo a Fazenda Pública o tribunal arbitral se depare com um forte indício de corrupção praticado por uma ou ambas as partes envolvidas no procedimento. São situações sensíveis e que podem, de fato, acontecer.

Imaginemos, por exemplo, que uma das testemunhas aponte que determinado contrato envolveu pagamento de propina para agentes públicos, ou que houve pagamento de comissão de intermediários, ou que no curso de um procedimento seja deflagrada uma operação policial de ampla divulgação midiática apresentando provas robustas de corrupção pelas autoridades, ou que uma das partes alegue nulidade do contrato indicando o pagamento de suborno ou comissões a intermediários do contrato. Esse espectro de possibilidades é lamentável e igualmente problemático.

Todos esses episódios podem acontecer e procedimentos arbitrais com a participação da Fazenda Pública não estão blindados desse tipo de problema e nunca estarão absolutamente seguros, mas um protocolo de política anticorrupção aplicado à arbitragem no espaço público pode suavizar as perdas da potestade e dos destinatários da administração pública. O que fazer nesses casos? Como os árbitros devem agir? Há um protocolo nacional de diretrizes anti-corrupção orientando a arbitragem na administração pública?

\section{A PRÁTICA INTERNACIONAL: O USO DA METODOLOGIA RED FLAGS.}

Diante do desafio de combater a corrupção, que não é enfrentado apenas no Brasil, mas em todo mundo, a comunidade internacional desenvolveu a metodologia "Red Flags". Essa metodologia é utilizada por árbitros diante de procedimentos arbitrais que levantam suspeitas de corrupção a partir da verificação de determinados comportamos ou fatos envolvidos no conflito. Com isso, cria-se mecanismos de gestão mais consistentes e transparentes para a confiança do comércio internacional e dos práticos da arbitragem.

As red flags, são sinais ou indícios que quando somados em uma relação contratual entre agentes públicos e/ou privados podem servir de ferramenta para que os árbitros verifiquem se há um risco ou presunção de corrupção e julgar o conflito levando em consideração tais aspectos (KHVALEI, 2013). Como se observa, a presença de uma red flag não identifica que existe corrupção ou outra prática criminosa, mas, representa condições ou situações associadas eventuais ilícitos.

Emmanuel Gaillard explica que essa metodologia vem de outras áreas, longe do contexto da arbitragem internacional, indicando que o uso dessa metodologia é bastante comum nos processos de due diligence $e^{7}$ comercial em processos de fusão e aquisição de empresas. Além disso, o autor faz referência a Lei de Práticas de Corrupção no Exterior (FCPA) publicada pela Comissão de Valores Mobiliários Norte-Americana que possui diretrizes detalhadas para o reconhecimento da corrupção onde enumera várias red-flags (GAILLARD, 2019, p.4).

\footnotetext{
${ }^{7}$ Due Diligence, significa uma análise realizada por determinada entidade ou companhia na preparação de uma transação comercial ou ainda como o conjunto de cautelas e investigações antecedentes a uma relação negocial ainda não concluída justamente para evitar prejuízos com a sua celebração.
} 
Assim, esse "sinal vermelho" pode ser identificado de diversas formas quando, por exemplo: existem altos índices de corrupção do país que sedia o contrato; uma das partes se negue injustificadamente a fornecer determinado documentos que poderia comprovar a licitude do contrato; se constate o pagamento de comissões para agentes públicos para formalização do contrato objeto do procedimento; houver taxa de participação ou pagamento de comissões sobre o valor final do contrato público; os serviços contratados foram pagos mas não realizados; houve grande brevidade da negociação para formalização de contratos complexos; os preços pagos são incompatíveis com a prática do mercado; existem altos índices de corrupção no país ou entidade estatal; ocorre incriminação de agentes públicos envolvidos pela autoridade policial; existem serviços pagos a empresas de fachada; há ausência de capacidade técnico/operacional de uma das partes para prestar o serviço contratado; constata-se ausência de registros (folhas de ponto dos funcionários, ausência de ata de reuniões, troca de correspondências ou e-mails) da prestação de serviços dentre outros e principalmente uma das partes aponta e demonstra que contrato foi produto de corrupção (BAIZEAU, HAYES, 2017, p. 248).

Como se observa, as red-flags constituem um conjunto de presunções de natureza processual previamente estabelecidas e desenvolvidas pelas melhores práticas internacionais que associadas a outras evidências específicas do caso concreto pode consubstanciar eventual ilicitude da contratação. Descarta-se, desde já, qualquer de decisão de cunho condenatório, arbitral ou judicial, fundada unicamente em red-flags. A metodologia não pode ser utilizada isoladamente. Não é meio de prova, na realidade, funciona como instrumento de obtenção de dados e subsídios de natureza informativa, que deve ser utilizada conjuntamente a outras provas.

Realmente, tais diretrizes internacionais não prevalecem sob presunção de inocência de índole constitucional e igualmente consagrada por diversos tratados internacionais, ao mesmo tempo que não deixa de servir de poderoso mecanismo orientador para o combate a corrupção por árbitros nacionais e estrangeiros.

As red-flags são indicativos, exemplos não exaustivos que em tese, podem configurar práticas corruptas cuja materialidade e autoria reclamam o direito ao contraditório e ampla investigação destinada a verificar elementos e subsídios consistentes, com o escopo de apurar, e se possível comprovar, em face do contexto do contratual, a eventual realidade fática-criminal dos eventos.

Uma reunião de todos esses sinais pode evidenciar a prática de corrupção diante do contexto negocial conflituoso levado à arbitragem. Muitas dessas informações podem ser identificadas durante a instrução do procedimento arbitral, sobretudo durante a fase de instrução onde há ampla produção de provas e na colheita de depoimentos de testemunhas e assistentes técnicos. Com efeito, se os árbitros verificarem a presença de uma ou mais red-flags, terão fortes indicadores de que o conflito arbitral envolveu a prática de crimes de corrupção.

\section{CASOS DE CORRUPÇÃO ANALISADOS POR CORTES ARBITRAIS}

O tema em âmbito internacional não é novo, existem algumas decisões arbitrais que analisaram casos de corrupção no âmbito internacional que podem ser considerados paradigmáticos. O resumo ilustrativo das hipóteses pode servir para a reflexão diante da construção evidenciada no título anterior, considerando a página em branca desse recorte regulatório no Brasil, já que conforme se poderá observar o Poder Público já participou de arbitragens que envolveram casos de corrupção.

\subsection{Caso World Duty Free v. Quênia.}

No procedimento ARB/00/7 administrado pela ICSID foi pleiteado ressarcimento decorrente de um investimento aportado pela Companhia que envolvia a construção de dois 
complexos aeroportuários no país africano. Um em Nairóbi outro em Mombaça. Passados alguns anos, o novo governo queniano expropriou os complexos e a Companhia instaurou arbitragem.

Durante o procedimento noticiou-se que o CEO da companhia ofereceu o pagamento de 2 milhões de dólares como 'doação pessoal' ao Presidente então do Quênia Toroitich Moi como forma de estimular a celebração do negócio. Após tomar ciência dessas informações, o Quênia tentou encerrar o procedimento, alegando que, como o contrato havia sido adquirido por meio do pagamento de suborno deveria ser considerado nulo e inexequível.

A questão era delicada, ao ponto do Quênia tentar tornar o caso confidencial.

O Tribunal rejeitou tal solicitação apontando que "especialmente em uma arbitragem da qual um governo é parte, não se pode presumir que a Convenção e o Regulamento de Arbitragem incorporem uma obrigação geral de confidencialidade que exigiria que as Partes se absterem de discutir o caso em público".

Outra questão interessante é que os árbitros entenderam a análise da corrupção como questão de mérito e não de jurisdição. Isso indica que inserida numa relação contratual, a ilicitude e suas consequências podem ser analisadas na própria arbitragem.

Ao fim, o Tribunal declarou-se competente para analisar a causa. Decidiu também que os fatos em torno da alegação de suborno não eram objeto da arbitragem e, por estar demonstrado que o pagamento da propina de fato ocorreu, o tribunal considerou que o contrato era nulo e negou provimento ao pedido ressarcimento da WDF, destacando que a corrupção "violava a ordem pública internacional" (ITALAW, 2000).

\subsection{Caso CCI n. 6497}

Em 1994 o tribunal examinou um outro caso envolvendo corrupção. No procedimento foi relatado que durante um período de aproximadamente uma década, as partes celebraram uma série de contratos de consultoria denominados como "Acordos Básicos". O escopo desses acordos envolvia a intermediação do requerente para o requerido obter contratos de construção em vários países, incluindo um determinado país ' $\mathrm{X}$ ' 'no Oriente Médio.

O litígio surgiu quando não foi efetivado o pagamento de um desses acordos. A parte demandante requereu o pagamento do montante, enquanto o requerente alegou que nenhum pagamento era devido, porque o objetivo real dos acordos era subornar funcionários no país X.

Na sentença arbitral, alguns dos contratos foram considerados válidos devido à ausência de prova convincente de corrupção. O Tribunal ponderou que "um tribunal civil, e em particular um tribunal arbitral, não tem o poder de fazer um inquérito oficial e não tem o dever de procurar de forma independente a verdade. Um tribunal civil tem de ouvir as alegações e as provas oferecidas pelas partes. A parte que alega a existência de corrupção tem o ônus da prova. Se a sua demonstração não é convincente, o tribunal deve rejeitar seu argumento, mesmo se o tribunal tiver algumas dúvidas sobre a possível natureza de suborno dos acordos".

No entanto, em um dos contratos o Tribunal observou que o requerente, segundo os termos do acordo, deveria obter uma comissão "extraordinária" de 33,33\% para garantir um negócio de construção nesse determinado país. O Requerente - apesar de sustentar que os serviços haviam sido cumpridos integralmente - não descreveu qual a natureza de tais serviços.

O Tribunal considerou que o Requerente deu explicações "confusas e contraditórias" sobre a natureza do acordo e dos serviços durante a audiência de instrução; observou ainda que havia um "alto grau de probabilidade de que o verdadeiro objetivo do acordo fosse canalizar propinas a autoridades do país X", Assim, "tal probabilidade é alta o suficiente" para considerar tal acordo como nulo e sem efeito (GAILLARD, 2019, p. 5).

\subsection{Caso CCI n.1100}


O conflito envolveu um contrato celebrado entre uma companhia britânica e um engenheiro portenho que intermediou a venda equipamentos para produção de energia elétrica junto ao governo argentino (CURY, 2019).

$\mathrm{O}$ engenheiro instaurou a arbitragem buscando pagamentos de comissões incidentes nos diversos contratos de fornecimento de energia. Comenta-se que o seu "grande trunfo" era o notável grau de influência que detinha com os alguns políticos que facilitaram a celebração desses contratos (BORN, 2019). Ocorre que tais comissões serviam, na verdade, para pagamento de suborno do requerente.

Houve ampla produção de prova no procedimento. Ambas as partes juntaram documentos, apresentaram manifestações e diversas testemunhas foram ouvidas.

$\mathrm{O}$ árbitro considerou que as leis nacionais vedavam o uso da arbitragem quando constada a violação a ordem pública e aos bons costumes, reservando essas questões à análise dos tribunais estatais.

Para o árbitro único ficou evidenciado, a partir das provas produzidas, que o acordo que ensejou o procedimento entre as partes contemplava o suborno de funcionários argentinos com o propósito de celebrar os contratos.

Durante a ouvida de testemunhas extraiu-se que "todos que desejavam fazer negócios na Argentina se deparavam com a questão de subornos, e que a prática de dar comissões a pessoas em posição de influenciar ou decidir sobre os contratos públicos parecem ter sido mais ou menos aceitos ou pelo menos tolerados na Argentina naquela época".

Na sentença, ainda que não sem fazer referência expressa a kompetenz-kompentz, o árbitro Lagergren entendeu que deveria analisar, antes de qualquer outra questão, a sua própria competência.

Ao fim decidiu que o conflito não poderia ser resolvido por arbitragem. Alguns trechos da sentença são dignos de nota:

Embora essas comissões não devessem ser usadas exclusivamente para subornos, uma parte substancial delas foi destinada a esse uso. Quer se esteja adotando o ponto de vista do bom governo ou o da ética comercial, é impossível fechar os olhos ao provável destino de valores dessa magnitude e ao efeito destrutivo do mesmo no padrão de negócios, com consequente prejuízo do progresso industrial. Tal corrupção é um mal internacional; é contrário à boa moral e a uma política pública internacional comum à comunidade das nações. Antes de invocar a boa moral e a ordem pública como impedindo que as partes recorram a instâncias judiciais ou arbitrais para resolver suas disputas, deve-se tomar cuidado para que uma parte não seja capaz de colher os frutos de sua conduta desonesta, enriquecendo-se despesa do outro. Nenhum efeito pode ser dado a contratos proibidos por lei ou contrários à boa moral e à ordem pública. Depois de pesar todas as evidências, estou convencido de que um caso como este, envolvendo violações tão grosseiras da boa moral e da política pública internacional, não pode ter fôlego em nenhum tribunal, seja na Argentina ou na França, ou, em outro país civilizado, nem em qualquer tribunal arbitral. Assim, a jurisdição deve ser recusada neste caso. (TRANS-LEX, tradução livre)

Como se observa o árbitro entendeu que não tinha jurisdição para solucionar o contrato objeto do conflito porque este havia sido celebrado em um contexto de corrupção envolvendo agentes públicos e privados. 


\subsection{Caso CCI n.13914}

O caso envolveu uma disputa decorrente de um acordo para aquisição de pesquisas sísmicas na costa de um país africano. O tribunal considerou que um número relevante de red-flags estavam presentes, incluindo uma alta taxa de sucesso no acordo, a falta de experiência do agente no negócio sísmico.

Durante o procedimento houve recusa de uma das partes em produzir documentos solicitados pelos árbitros, em especial os registros das transações financeiras e bancárias o que ensejou a desconfiança dos árbitros acerca da legalidade do contrato. O tribunal observou que havia provas convincentes de que a comissão paga pelo demandado ao demandante deveria ser usada para subornar funcionários do Estado a fim de obter o contrato.

Enfim, as red-flags, juntas, indicavam que o objeto do acordo era na realidade o pagamento de subornos aos dirigentes da empresa estatal para influenciar sua tomada de decisão para aquisição e investimentos nas pesquisas objeto do contrato (GAILLARD, 2019, p.6). Na sentença arbitral, os árbitros decidiram que os acordos eram ilícitos, que contrato de consultoria era inválido e negaram todos os pedidos apresentados.

\section{A TENDÊNCIAS NO ÂMBITO NACIONAL}

A pergunta que se impõe é: constatado diversos indícios de corrupção o que fazer? A doutrina internacional aponta algumas posturas que podem ser tomadas pelo tribunal arbitral: uma passiva e ou ativa (RAOUD, 2009).

A postura passiva do árbitro se dá quando este recusa-se em combater a corrupção. Argumenta-se que o árbitro é sujeito privado que exerce função pública, mas não detém autoridade judicial para combater, reprimir ou julgar corrupção. Assim, ao se deparar com um caso de corrupção o árbitro encaminha a questão para as autoridades estatais e julga-se incompetente, encerrando a arbitragem.

Especialistas indicam que historicamente há uma relutância por parte dos tribunais arbitrais para lidar com questões de corrupção, pois os árbitros não se sentem à vontade para investigar indícios de corrupção, principalmente quando nenhuma das partes levanta a questão ou pior: quando ambas estão envolvidas na negociação ilícita (CAVE, 2019).

Os árbitros tendem a focalizar a natureza consensual do processo e de sua nomeação que impede qualquer iniciativa investigativa ou punitiva. Ademais, a preferência dos árbitros pela neutralidade muitas vezes decorre do fato de que a investigação dos sinais de corrupção, mesmo que provada, pode não afetar o resultado da sentença arbitral, em função da natureza de ordem estritamente técnica suscitada no conflito (CAVE, 2019).

Não há que se falar em consenso no que diz respeito a essa posição no contex to dogmático dos debates que têm sido incutidos recentemente, já que há uma segunda corrente numa extremidade mais próxima do direito privado pode defender o silêncio da arbitragem diante da verificação de ato ou negócio que configure corrupção, mantendo posição volitiva de cercear a comunicação das autoridades de controle do Poder Público sobre o fato.

Segundo Adam Kaufmann, "a arbitragem é um meio privado de solução de conflitos, portanto, se o árbitro verificar que uma das partes cometeu alguma forma de corrupção, não tem o dever de notificar as autoridades". Com efeito, "o árbitro só deve se preocupar com as partes da disputa e é excessivo lhe exigir que denuncie corrupção à Autoridade Policial ou ao Ministério Público. Mais ainda, "ao notificar um crime, o árbitro violaria a confidencialidade do procedimento” (RODAS, 2019).

Nessa perspectiva argumentativa, a arbitragem está inserida num contexto que desvia da noção de indisponibilidade do interesse público que agrega o regime jurídico e os marcos 
normativos próprios das relações entre o Estado e todos os atores privados com os quais se relaciona.

Segundo essa visão, a quebra da reserva arbitral pode configurar a responsabilidade criminal de árbitros, cuja atividade arbitral venha a se desenvolver como desdobramento da advocacia, considerando a tipificação do artigo 154 do Código Penal ${ }^{8}$. Tratar-se-ia da violação do segredo profissional, uma vez que a dinâmica mantida em meio a comunidade empresarial enseja determinados problemas para cuja solução é necessário recorrer a terceiros, sujeitos qualificados técnica e profissionalmente. Assim, esses problemas devem ser mantidos em sigilo não só em benefício do confidente, mas da própria convivência social ou dos interesses de ordem moral, social e ou econômica. Ao revelar, sem justa causa, segredo de teve conhecimento em razão de função, ministério, ofício ou profissão, o árbitro enquadrar-se-ia no tipo penal acima exposto (CATERJI, 2017).

Essa postura é bastante questionável e não encontra respaldo em nossa legislação como poderemos observar mais adiante.

Deve-se considerar que essa postura indiferente faria com que a arbitragem fosse usada para convalidar ou dar verniz de legalidade a uma contratação que, o Ministério Público, o Tribunal de Contas ou a Autoridade Policial denotariam como ato ou negócio ilegal. Nesse caso, a arbitragem poderia se tornar instrumento para transações corruptas, tornando-se ferramenta jurisdicional destorcida deturpada e possivelmente indutiva de fraudes privilegiadas pela acolhida dessa alçada decisória.

Essa postura passiva da arbitragem diante de demandas de natureza pública já tem sido criticada, como é possível observar na assertiva de César Pereira: "a gravidade da constatação de práticas corruptas nos fatos submetidos ao julgamento dos árbitros impede que estes se omitam. $\mathrm{O}$ tema é complexo e não há solução simples para o dilema".

Contudo, a posição de defesa de uma postura ativa da arbitragem no combate à corrupção só se tornará um imperativo categórico se sua defesa sair do plano de uma corrente dogmática ou da defesa ideológica, pois abrindo um espaço retórico é possível defender o viés anticorrupção da arbitragem sem ponderar as dificuldades, sem preconceitos e saídas justiceiras, mas quando o registro da corrupção impactar no direito aplicável às partes, é provável que os atores privados cedam parte do encantamento que lhes seduziu diante da propositura da cláusula arbitral (PEREIRA, 2019).

A mediana associada ao argumento de Cesar Pereira pode representar um calço para o desenvolvimento de uma interface que começa a ser induzida no Fórum econômico de Davos, realizado em janeiro de 2020 na Suíça, pois as perdas em trilhões de dólares para o mercado internacional podem suavizar a selvageria inerente as buscas do capitalismo, abrindo alas para um protocolo internacional de política anticorrupção que as grandes empresas já aplicam como rotina de controle interno, ou seja, compliance ${ }^{9}$.

\footnotetext{
${ }^{8}$ Art. 154 - Revelar alguém, sem justa causa, segredo, de que tem ciência em razão de função, ministério, ofício ou profissão, e cuja revelação possa produzir dano a outrem: Pena - detenção, de três meses a um ano, ou multa.

${ }^{9} \mathrm{O}$ compliance "é um conjunto de regras, padrões, procedimentos éticos e legais, que, uma vez definido e implantado, será a linha mestra que orientará o comportamento da instituição no mercado em que atua, bem como a atitude dos seus funcionários". CANDELORO, Ana Paula; RIZZO, Maria Balbina Martins de; PINHO, Vinícius. Compliance $\mathbf{3 6 0}^{\circ}$ : riscos, estratégias, conflitos e vaidades no mundo corporativo. São Paulo: Trevisan Editora Universitária, 2012, p. 30. Não se restringe, portanto, ao mero cumprimento - comply - de regras formais, se destina às ferramentas de concretização da missão, da visão e dos valores de uma instituição $\mathrm{O}$ instituto engloba temas estratégicos e se aplica a todos os tipos de entidade, na medida em que o mercado exige cada vez mais condutas éticas e consolidação das melhores práticas por parte das organizações . Aliás, as câmaras de arbitragem são prestadoras de serviços privado e exercem atividade essencialmente empresarial. Estão, assim, sujeitas à ética empresarial, isto é, aquela que se espera do agente probo e consciente dos avanços atingidos e compromissos assumidos pela empresa na sociedade moderna. Cf. GIUSTI, Gilberto. A Ética das Instituições de Arbitragem. Revista Brasileira de Arbitragem. n. 40. São Paulo: Editora Revista dos Tribunais, 2016 p. 80
}

Revista de Direito Brasileira | Florianópolis, SC | v. 27 | n. 10 | p.241-261 | Set./Dez. 2020 
Nesse espaço pluridogmático de construção, uma terceira via ensaia postura ultrapublicista, sugerindo que o árbitro tem o dever corrigir práticas corruptas, atuando como "guardião das leis e tratados", exercendo uma postura ativa. Essa posição enseja a continuação do procedimento arbitral e a responsabilização civil dos envolvidos. No caso n. 14920 da Corte de Comércio Internacional (CCI), por exemplo, restou apontado que todos os árbitros têm a obrigação de se opor seriamente à corrupção.

Nesse caso, se forem descortinadas hipóteses de corrupção durante a arbitragem, deve-se considerar que a transação legal subjacente ao diagnóstico, que ignora a(s) prática(s) corrupta(s), prejudicam a decisão do litígio, por isso o árbitro não pode ignorar esses fatos, pelo contrário, deve investigar, coletar argumentos e evidências para confïmar ou rejeitar as acusações e avaliar suas implicações no caso (BULLETIN, 2013).

Resumindo as correntes levantadas no que tange a condução da arbitragem diante do risco de corrupção que é inerente às conexões cada vez mais diversificadas e profundas da Administração Pública com o setor privado, podemos chegar a seguinte representação:

\begin{tabular}{|c|l|}
\hline $\begin{array}{c}\text { Posições da arbitragem diante da } \\
\text { corrupção }\end{array}$ & \multicolumn{1}{c|}{ Bases de argumentação } \\
\hline Posição ultraprivatista & $\begin{array}{l}\text { O árbitro deve guardar sigilo mesmo diante da } \\
\text { evidência de ação ou fato criminoso; não tem } \\
\text { o dever de notificar as autoridades e caso } \\
\text { releve estaria violando o sigilo inerente a } \\
\text { profissão }\end{array}$ \\
\hline Posição mediana & $\begin{array}{l}\text { O árbitro ao se deparar evidência de ação ou } \\
\text { fato criminoso deve garantir às partes o } \\
\text { exercício do contraditório e encaminhar a } \\
\text { questão para às autoridades competentes. }\end{array}$ \\
\hline Posição ultrapublicista & $\begin{array}{l}\text { O árbitro deve combater práticas corruptas, } \\
\text { exercendo uma postura ativa e } \\
\text { responsabilizando civilmente os envolvidos. }\end{array}$ \\
\hline
\end{tabular}

Fonte: Autor, 2020.

Com três correntes abertas, o percurso que pode se apresentar com outras variáveis num caminho longo na amarração de uma tese lúcida para resguardar o interesse público. Para manter os capitalistas devidamente agasalhados, um questionamento seria cabível, qual seja: e se arbitragem fosse suspensa diante de fortes indícios de corrupção?

Nesse ponto, é necessário considerar que a suspensão da arbitragem pode desvirtuar o seu propósito, já que a tramitação do processo penal voltada à apuração da corrupção pode se protrair no tempo e o inusitado poderia se apresentar quando uma das partes levantasse alegação de corrupção da outra com o simples intuito de evitar responsabilização por descumprimento contratual ou adiar indefinidamente o resultado do procedimento arbitral (KHVALEI, 2013, p. 23).

Nesses casos aconselha-se que os árbitros resolvam o conflito levando a efeito a postura corrupta de uma das partes. Ao adotarem essa postura, os árbitros não devem suspender o procedimento de arbitragem e encaminharem as provas para a autoridade policial ou Ministério Público para que se proceda com a investigação e apuração dos fatos. 


\section{APLICAÇÕES ESPECÍFICAS COM BASE NO DIREITO BRASILEIRO}

\subsection{A verificação pelos árbitros da ocorrência de um tipo penal praticado pelas partes}

A Lei de Arbitragem não refere de forma explícita do sigilo do arbitro diante de eventuais indícios de corrupção de uma das partes ou mesmo de ambas, considerando os dois litigantes considerados no conflito, mas estipula no artigo $13, \S 6^{\circ}$ que o no desempenho de sua função, o árbitro deverá proceder com discrição.

Os limites do sigilo podem ter ficado fora da pauta do legislador diante de acordo com uma estratégia pós-positivista muito afetada ao direito público contemporâneo, mas seria possível supor que a omissão legislativa pode ser interpretada na assertiva a seguir? O dever de discrição impede legalmente o árbitro de revelar qualquer informação relacionada à arbitragem em que atue ou que tenha atuado.

Vamos refletir numa perspectiva neoconstitucionalista do direito administrativo e observar o artigo $2^{\circ} \S 3^{\circ}$ Lei 13.129/2015 (LARB), observando a imposição do princípio da publicidade no contexto da norma referida. A ausência de um dispositivo que vincule todos os atores da arbitragem ao dever de transparência talvez não seja suficiente para positivar a hipótese do parágrafo anterior, afastando a agregação da arbitragem aos tentáculos do polvo que abarca a política anticorrupção numa cadeia de diretrizes multifacetadas.

De fato, são muitos os atores envolvidos na arbitragem (partes, advogados, peritos, árbitros, instituições arbitrais) e os degraus do processo também podem ser diferentes (no requerimento de arbitragem, nas alegações iniciais, na apresentação e produção de documentos, a realização de eventual perícia ou apenas a sentença). Considerar os sujeitos e as fases desse relacionamento é importante para pensar sobre o alcance do dever de transparência na arbitragem.

Nesse contexto, o Enunciado n. 4 da I Jornada Prevenção e Solução Extrajudicial de Litígios prevê que cabe à Administração Pública promover a publicidade do procedimento observado o disposto na Lei n. 12.527/2011, podendo ser mitigada nos casos de sigilo previstos em lei, a juízo do árbitro. Essa interpretação, a princípio, exime as instituições arbitrais de divulgar a existência de procedimentos, atribuindo apenas e tão somente a parte pública de promover a publicidade da arbitragem.

A interpretação no direito administrativo apresenta tendências neoconstitucionais que podem abrir caminho para a construção do dever de transparência do arbitro com base no caráter público da jurisdição, como também não seria impossível que a edição de uma ato normativo, regulamentando o princípio da publicidade no contexto da política anticorrupção, fosse uma alternativa plausível para arrematar o ideal de publicização da arbitragem nos contratos públicos e demais temáticas da fazenda pública.

No momento, a ressaca do direito administrativo do medo diante de um ambiente de baixa segurança jurídica podem ser a base de uma exegese mais hermética que fica de costas não só para o regime jurídico administrativo, como também para o arremate de uma política nacional de integridade importante para o salto do Brasil no olhar da OCDE e, por conseguinte, do próprio mercado.

Por enquanto, a interpretação privatista também pode ser considerada válida, ou seja, no curso de arbitragem em sede de demanda de natureza pública, o arbitro ainda pode se eximir de conhecer de eventuais fatos, atos ou negócios que reportem uma das partes ou ambas, considerando a tipificação de hipótese administrativa ou criminal de corrupção.

De forma paralela à interpretação da LARB no contexto mais apegado ao direito privado, temos que realçar a regulação da matéria numa dimensão sistemática. De acordo com os artigos 25, 36 e 37 do Código de ética da OAB que dispõe sobre a atuação do advogado, no exercício da 
função de árbitro, dispondo sobre a submissão do patrono ao dever de guardar sigilo dos fatos de que tome conhecimento no exercício da profissão.

A exceção se aplica em face de circunstâncias excepcionais que configurem justa causa, como nos casos de grave ameaça ao direito à vida e à honra, ou que envolvam defesa própria. Acerca dessas questões alerta-se que:

com objetivo de identificar se poderá ser penalmente responsabilizado o árbitro advogado que deixar de comunicar às autoridades eventual prática futura de crime, é importante também recordar que a imputação criminal, seja na qualidade de autor ou de partícipe, somente poderá ocorrer a partir da adequação, entre outros, dos dispositivos que tratam do concurso de crimes, artigo 29 e seguintes, e da própria relação de causalidade da conduta com o resultado típico, disciplinada no artigo 13, todos do Código Penal ${ }^{10}$.

Lado outro, o Brasil ratificou a Convenção das Nações Unidas contra a Corrupção através do Decreto n. 5.687/2006, e conforme se observou "tal convenção, inclusive, apresenta, em seu artigo 34, a mesma consequência jurídica que a Lei 8.666/1993 para os atos de corrupção em relação aos contratos em que estão inseridos:

[...] os Estados Partes poderão considerar a corrupção um fator pertinente em procedimentos jurídicos encaminhados a anular ou deixar sem efeito um contrato ou a revogar uma concessão ou outro instrumento semelhante, ou adotar qualquer outra medida de correção (CURY, 2019).

Ademais, nos termos do art. 40 do Código de Processo Penal “quando, em autos ou papéis de que conhecerem os juízes ou tribunais verificarem a existência de crime de ação pública, remeterão ao Ministério Público as cópias e os documentos necessários ao oferecimento da denúncia". O dispositivo cuida de situação em que a autoridade jurisdicional tenha ciência de fatos que são aparentemente criminosos, por isso a discussão sobre a abrangência do dever de sigilo ou as balizas de transparência possuem utilidade significativa e podem levantar as justificativas necessárias para a construção da autorização ou obrigação de remessa dos autos à autoridade

\footnotetext{
${ }^{10}$ Interessante artigo abordou de forma precisa essas questões" A regra geral de que o dever de sigilo dos árbitros decorre do contrato das partes encontra ainda uma outra exceção - que é o objeto precípuo deste artigo -, vinculada aos ditames específicos do exercício profissional da advocacia, cuja aplicação se estende à situação particular da atuação do advogado como árbitro, quando regularmente inscrito na Ordem dos Advogados do Brasil. Para tal situação, há norma especial, de ordem pública, determinando impositivamente o sigilo, mesmo que a contratação das partes assim não o estabeleça. No que tange à advocacia, o sigilo é indissociável da própria atividade profissional. Trata-se de garantia não apenas ao cliente e ao advogado, como à própria cidadania e ao sistema de justiça. Conforme referido por Paulo Roberto de Gouvêa Medina15: "É importante notar que a preservação do sigilo profissional implica, ao mesmo tempo, para o advogado, um dever que visa à proteção do segredo que lhe tenha sido confiado e uma prerrogativa, que o põe a salvo de qualquer contingência em que, porventura, se veja constrangido a revelá-lo. Tratase, portanto, de um direito-dever - ou, mais precisamente, como, a seguir, procuraremos demonstrar, de um devergarantia”. A Lei Federal 8.906 de 04.07.1994, que dispõe sobre o Estatuto da Advocacia, reza em seu artigo 33, parágrafo único, que o advogado "obriga-se a cumprir rigorosamente os deveres consignados no Código de Ética e Disciplina". No artigo 34, VII, do mesmo diploma legal é previsto inclusive como infração disciplinar a violação do sigilo profissional, a qual está sujeita à multa, censura, suspensão ou até exclusão dos quadros da $\mathrm{OAB}$, no caso de reincidência (arts. 36, II, 37, II, e 38, I). No artigo 54, V, da mesma Lei Federal é conferida competência ao Conselho Federal da OAB para editar e alterar o Código de Ética e Disciplina da Ordem dos Advogados do Brasil (CED-OAB). Em relação ao CED-OAB, com novel redação em vigor desde 02 de maio de 2016, esse determina, em seus artigos 35 e 36, que "o advogado tem o dever de guardar sigilo dos fatos de que tome conhecimento no exercício da profissão", sendo tal sigilo "de ordem pública, independendo de solicitação de reserva que the seja feita pelo cliente" cf: CANTERJI, Rafael Braude; RANZOLIN, Ricardo. Dever de Sigilo do Advogado Quando Atua Como Árbitro no Direito Brasileiro. Revista de Arbitragem e Mediação n. 53. São Paulo: Editora Revista dos Tribunais. 2017.
} 
competente do Estado quando os árbitros tomarem conhecimento da tipificação de crimes durante o processo arbitral (VERÇOSA; MONEGALHA, 2019).

Nesse sentido Cesar Pereira (2019) refere o seguinte:

no caso das arbitragens envolvendo à Administração Pública, sujeitas ao princípio da publicidade, não se põe a objeção da confidencialidade e não deveria haver dúvida quanto ao dever de comunicação dos fatos ilícitos apurados, exceto se, instadas pelos árbitros, as partes demonstrem que se trata de fatos já apurados ou em investigação em procedimentos externos à arbitragem, ou se o fato já houver sido ou puder ser objeto de comunicação por iniciativa das partes ou de terceiros em posição que prefere à dos árbitros.

A título de referência, a Lei de Mediação quando trata das exceções à confidencialidade estipula que toda e qualquer informação relativa ao procedimento de mediação será confidencial em relação a terceiro. No entanto, o mesmo diploma dispõe que a regra de confidencialidade não se aplica a informação relativa à ocorrência de crime de ação pública (Lei 13.140/15, artigo 30 e $\S 3^{\circ}$ ). Ou seja, relatar a ocorrência crime não viola o dever de confidencialidade nesse procedimento privado.

Entendemos que o árbitro pode realizar determinadas análises de iniciativa própria sempre garantindo às partes a oportunidade de participação e manifestação quanto aos dados coletados. Assim garante-se a ampla defesa e evita-se qualquer decisão surpresa quanto à questão (PEREIRA, 2019). E, seja como for, terá o dever de seguir o disposto no art. 40 do Código de Processo Penal pois sobre si recai não apenas os poderes, mas também os deveres decorrentes da função que livre e conscientemente aceitou.

Ademais, deve-se ressaltar que a contratação envolvendo corrupção não enseja a nulidade da convenção de arbitragem nos termos do art. $8^{\circ}$ da Lei de Arbitragem. A cláusula compromissória é autônoma e independente em relação ao contrato no qual ela está inserida e, portanto, continuará válida, mesmo se o tribunal arbitral decidir que o contrato principal é nulo porque envolve ilícito penal (RAOUD, 2009).

Qualquer uma das partes, seja ente público ou privado não pode se beneficiar de uma nulidade que ela mesma provocou; subornar ou aceitar suborno para alegar nulidade do contrato e, posteriormente, eximir-se de obrigações ainda que de natureza reparatória. Realmente, o árbitro pode decidir a demanda, nos estreitos limites da arbitrabilidade objetiva que ela envolve e levando a efeito a ilegalidade contratual, sem que isso implique em nulidade de sua sentença, violação seu dever de discrição ou mesmo extrapolação dos seus poderes de decisão (LARB, art. 18)

Nessa conjuntura, a corrupção é decorrente de contrato tem natureza negocial e pode ser tratada no procedimento arbitral sem prejuízo de eventuais responsabilizações em âmbito administrativo e penal dos envolvidos. Repita-se: a existência ou indícios de corrupção ou outros crimes, por si só, não impede o prosseguimento do procedimento arbitral nem tampouco a análise do mérito pelos árbitros.

Acreditamos que o árbitro, ao remeter tais documentos para o Ministério Público, de forma alguma está antecipando sua opinião, ou pré-julgamento sobre o comportamento da parte. Seguindo a legislação processual penal em vigor, o árbitro não estará maculando sua imparcialidade ou qualidade de julgador privado. Mais ainda, estará resguardando o procedimento arbitral de qualquer nulidade ou intervenção judicial a posteriori. Deve-se ressaltar que ao proceder nos termos do art. 40 do CPP caberá ao Ministério Público Federal ou Estadual, de acordo com sua respectiva competência, tomar qualquer iniciativa persercutiva que pode ou não acontecer.

O sigilo na arbitragem não é uma regra absoluta ainda mais quando o instituto se apresenta na caixa de ferramentas da Administração Pública, que está submetida a parâmetros de transparência passiva e ativa de acordo com a Lei 12.527/11. Ademais, o CPP não ordena a 
suspensão do procedimento, fala apenas que se encaminhe cópias dos autos para a autoridade competente

Pode-se questionar então que, nos termos da legislação brasileira, identificado a existência de crime ou fortes indícios de deste, em especial os de corrupção, o árbitro (advogado ou não) deve encaminhar as cópias procedimento para o Ministério Público? Nos termos da legislação processual penal, a resposta é positiva e de forma alguma tal ação violaria a confidencialidade do procedimento que pode seguir em absoluto segredo de justiça.

Mesmo em arbitragens não submetidas ao princípio da publicidade, a realização dos valores fundamentais do combate à corrupção e à atividade criminosa e a proteção da própria legitimidade e dignidade da arbitragem prevalecem em relação à confidencialidade e permitem a aplicação do art. 40 do CPP, observados os limites reconhecidos para tal dispositivo no âmbito do processo penal e a equiparação prevista no art. 17 da Lei $\mathrm{n}^{\circ}$ 9.307.21 Tal como as exigências relativas à apuração, provocada ou de ofício, dos fatos relativos à conduta corrupta, a observância do dever de comunicação favorece a arbitragem na medida em que minimiza a hipótese na qual essa jurisdição se constitui como um instrumento para a ocultação de práticas ilícitas" (PEREIRA, 2019).

Isso nos leva a crer que se o árbitro se deparar com uma circunstância criminosa ou prática de ilícito penal no conflito não precisará suspender ou tampouco encerrar o procedimento de arbitragem. Deve apenas seguir a ordem estipulada no CPP, qual seja: comunicar o Ministério Público sobre a existência de crime.

Em âmbito internacional, recomenda-se que a relação entre arbitragem e direito penal não deve ser de confronto. $O$ combate a corrupção na arbitragem contribui para a instituição de ordem pública internacional, e nesse sentido os árbitros podem ser vistos como os verdadeiros guardiões da legalidade e dos bons costumes no comércio internacional como propõe Alexis Mourre.

Para o autor, a postura do árbitro não repercute apenas no procedimento que foi designado, mas também para a toda a comunidade empresarial internacional. Mourre (2006) bem destaca que no mercado mundial, boas práticas, governança, ética e transparência são indispensáveis para garantir as corporações o acesso amplo aos mercados e condições justas de concorrência. E conclui afirmando que se a arbitragem se tornasse um porto seguro para a ilegalidade ou uma ferramenta para fraude, ela seria rejeitada não apenas pelos Estados, mas também deixaria de ser recomendável para a comunidade empresarial e, portanto, adequada de resolver disputas comerciais internacionais.

Os árbitros, apesar de não deterem os mesmos poderes coercitivos que os juízes estatais, ou os mesmos instrumentos de investigação que os membros do Ministério Público para investigar, podem servir como um relevante ator de combate à corrupção relatando às autoridades competentes ilegalidades, corrupção e outros crimes no âmbito das contratações e conflitos em que participe a Fazenda Pública (CURY, 2019).

\subsection{A corrupção praticada pelo árbitro}

A Lei de Arbitragem dispõe que os árbitros são juízes de fato e de direito, quando no exercício de suas funções e são equiparados aos funcionários públicos, para os efeitos da legislação penal. Assim, para além dos poderes jurisdicionais, o árbitro detém responsabilidades e caso atue de forma ilícita estará sujeito à aplicação de tais penalidades ao fazer alusão Código Penal o legislador procurou proteger não apenas a administração pública, mas também as partes contra a prática de concussão, de corrupção e de prevaricação.

A tipificação das condutas aludidas compromete a atuação do julgador e torna nula sua decisão (CARMONA, 2009, p. 267). Nesse ponto, as implicações de crime praticado por árbitro são graves e podem comprometer não apenas ele próprio, mas também a instituição responsável pela administração do processo arbitral que pode não ter qualquer relação com o ilícito 
Se assim for, de um lado a sentença arbitral será nula nos termos do artigo 32, VI da LARB. De outro, o árbitro estará sujeito à responsabilização civil e penal tal como um magistrado criminoso. Acerca desse último ponto, cabe ressaltar que não será necessário o trânsito em julgado de eventual sentença penal condenatória para só então atestar a nulidade da decisão arbitral.

As partes precisam estar atentas ao prazo de 90 dias previsto no artigo 33 da LARB para manejar a ação anulatória e não poderão (nem devem) aguardar o fim de uma investigação ou processo penal para só então desconstituir o resultado da arbitragem: "independentemente da apuração dos crimes, pode a parte interessada, alegando ter ocorrido alguma das condutas tipificadas nos artigos referidos, promover a demanda desconstitutivo do laudo, produzindo no juízo cível a prova bastante para este efeito" (CARMONA, 2009, p. 408).

Por fim, cabe ressaltar ainda que uma instituição arbitral não pode ser responsabilizada e nem sobre si podem recair as repercussões negativas nos casos em que o árbitro agiu de forma ilícita, pois a câmara e o árbitro têm funções distintas e suas atividades não se confundem.

A parte ou seus advogados, ao noticiar esses fatos ao Ministério Público, que a toda evidência são relevantes, deve conhecer a dinâmica legal e identificar pormenorizadamente o incidente e o(s) possível(is) envolvido(s) de modo a evitar pré-julgamento ou mesmo confusão a respeito do assunto do qual, na maioria dos casos, se desconhece inteiramente. A corrupção do árbitro, sem qualquer margem de dúvida, deve levar a punição severa, mas não pode, sob qualquer hipótese, levar a ruína instituições sérias e de credibilidade atestada.

\subsection{A corrupção no momento da pactuação da cláusula compromissória}

A inserção de cláusula compromissória contrato elaborado para viabilizar a prática de ilícitos entre particulares ou entre particulares em conjunto com agentes da administração pública é, na realidade prova documental de um crime. Nesse contexto a cláusula é um dos instrumentos do complexo contratual. Trata-se de negócio jurídico nulo.

Imaginemos um contrato elaborado detalhada e dolosamente para prática de corrupção. Cientes previamente da confidencialidade da arbitragem, para evitar que qualquer questão venha, eventualmente, a ser apresentada em um processo judicial os agentes concordam em inserir cláusula compromissória com o escopo exclusivo de ocultar de maneira mais intensa o ilícito; o ânimo camuflar o contexto negocial criminoso e o objetivo é de evitar o acesso ao Judiciário, encobrindo o ilícito da publicidade do processo judicial.

Nessa perspectiva, não há como considerar válido ou extrair qualquer tipo de obrigação de natureza material ou processual de negócio escuso sob pena de se permitir a utilização da Arbitragem para o exaurimento e confirmação de um ajuste claramente indevido.

Convencionar arbitragem nesse ânimo de corrupção configura um ato ilícito. Se a convenção de arbitral é utilizada como instrumento negocial para prática de outros crimes será, como dito acima, negócio jurídico eivado de nulidade. E mais ainda: a fonte de poder dos árbitros estará viciada de não poderão ser extraídos quaisquer efeitos dela.

Sendo esse o caso, tão logo tomem conhecimento acerca desses fatos, não caberá aos árbitros fazer qualquer tipo de análise de mérito mas encerrar o procedimento imediatamente e, se assim entenderem, remeter a questão para as autoridades competentes. Realmente, qualquer decisão advinda de uma convenção arbitral desse tipo é nula nos termos do artigo. 32, I da Lei de Arbitragem.

\section{CONCLUSÕES}

A ampliação da utilização da arbitragem envolvendo a Administração Pública vem provocando, cada vez mais, a estudos e reflexões sobre o tratamento da corrupção por entidades e julgadores privados. Apesar da tímida análise dogmática sobre o tema, merecem especial destaque 
os julgamentos arbitrais e artigos abordando o assunto, o que já viabiliza o reconhecimento de balizas importantes para o estudo do tema do âmbito do direito administrativo e do direito arbitral.

A prática internacional desenvolveu uma metodologia específica para a verificação e combate a corrupção em arbitragens. A metodologia das red-flags estabelece alguns sinais ou mesmo indícios de determinadas práticas que possam levar ao reconhecimento de práticas ilícitas. As red-flags não identificam ação de corrupção ou outra prática criminosa, mas, representam presunções fortes que com base em evidências específicas associadas a eventuais ilícitos que podem auxiliar árbitros.

As cortes arbitrais internacionais, em mais de uma oportunidade, analisaram casos de corrupção. Os casos tomaram desfechos diversos. Existem decisões em que os árbitros julgaramse incompetentes para analisar casos de corrupção, como é o caso n. 1100 da CCI. Como também se pode verificar casos em que os árbitros extraíram as consequências civis dos ilícitos cometidos pelas partes como é caso n. 13.914 da também CCI.

Existem três posições possíveis a serem tomadas pelos práticos da arbitragem que variam da concepção ultraprivatista a ultrapublicista encontrando um ponto de equilíbrio numa posição mediana. Cada uma das concepções serve de guia orientador para o árbitro quando se deparar em uma possível prática corrupta no julgamento do caso do qual é responsável.

A legislação brasileira impõe ao árbitro, enquanto juiz de fato de direito e por ser, no exercício de tal função equiparado a funcionário público o dever de, ao verificar a existência de crime, remeter às autoridades competentes as cópias e os documentos necessários ao oferecimento da denúncia. Tal conduta, aliás, não enseja a quebra da confidencialidade ou tampouco enseja o pré-julgamento da demanda arbitral.

O combate a corrupção na arbitragem pode contribuir não apenas para atrair investimento estrangeiros e desenvolvimento econômico, mas também para inibir práticas ilícitas nos contratos celebrados pela Administração Pública. Assim, é possível compor um interessante e indispensável protocolo de política anticorrupção para a manutenção da ordem pública internacional.

\section{REFERÊNCIAS}

ABREU, Isabella. Entenda os impactos da operação Lava Jato na economia brasileira. Dinheirama. Disponível em: https://bit.ly/32Et99V/. Acesso em: 27/01/2020.

BAIZEAU, Domitille ; HAYES, Tessa. The Arbitral Tribunal's Duty and Power to Address Corruption Sua Sponte. International Arbitration and the Rule of Law: Contribution and Conformity. ICCA Congress Series. v. 19. Kluwer Law International 2017.

BREI, Zani Andrade. Corrupção: dificuldades para definição e para um consenso. Revista de Administração Pública, Rio de Janeiro, v. 30, n. 1, 1996. p. 67.. Acesso em: 28 Set. 2020.

BORN, Gary. Bribery and an Arbitrator's Task. Disponível em https://bit.ly/2TkTwgW /. Acesso em 10 de maio de 2019.

CANDELORO, Ana Paula; RIZZO, Maria Balbina Martins de; PINHO, Vinícius. Compliance $360^{\circ}$ : riscos, estratégias, conflitos e vaidades no mundo corporativo. São Paulo: Trevisan Editora Universitária, 2012.

CANTERJI, Rafael Braude; RANZOLIN, Ricardo. Dever de Sigilo do Advogado Quando Atua Como Árbitro no Direito Brasileiro. Revista de Arbitragem e Mediação n. 53. São Paulo: Editora Revista dos Tribunais. 2017. 
CARMONA, Carlos Alberto. Arbitragem e Processo: um comentário a Lei 9.307/96. 3 ed. São Paulo: Atlas, 2009.

CAVE, Bryan. Bribery and Corruption in International Arbitration. Disponível em: https://bit.ly/2Q4bF0p. Acesso em 10 de maio de 2019.

CONSELHO NACIONAL DE JUSTIÇA. Brasília. Justiça em Números 2019. Disponível em <https://bit.ly/2VvvZg6> 20 de janeiro de 2020.

Corrupção desvia U\$ 1 trilhão em impostos globalmente, diz FMI. GLOBO G1. Disponível em: https://g1.globo.com/economia/noticia/2019/04/04/corrupcao-desvia-u-1-trilhao-em-impostosglobalmente-diz-fmi.ghtml. Acesso em 04 de janeiro de 2020.

CURY, Antonio Alberto Rondina. Efeitos da corrupção em arbitragens envolvendo o poder público. Revista de Arbitragem e Mediação. n. 60. São Paulo: Editora Revista dos Tribunais, 2019.

DIAS, Maria Tereza Fonseca. Direito Administrativo pós-moderno: novos paradigmas do direito administrativo a partir do estudo da relação entre o Estado e a Sociedade. Belo Horizonte: Mandamentos, 2003.

FORTINI, Cristiana. MOTTA, Fabrício. Corrupção nas licitações e contratações públicas: sinais de alerta segundo a Transparência Internacional. Revista de Direito Administrativo \& Constitucional. n. 64, p. 93-113. Belo Horizonte: Editora Fórum, 2016.

GAILLARD, Emmanuel. The emergence of transnational responses to corruption in international arbitration. Arbitration International v. 35 n. 1. Oxford University Press, 2019.

GIUSTI, Gilberto. A Ética das Instituições de Arbitragem. Revista Brasileira de Arbitragem. n. 40. São Paulo: Editora Revista dos Tribunais, 2016.

GRINOVER, Ada Pellegrini. Arbitragem e prestação de serviços públicos. Revista de Direito Administrativo, v. 233, p. 377-385, 2003.

Ensaio sobre a processualidade: fundamentos ara uma nova teoria geral do processo. 1 ed. Gazeta Jurídica. Brasília, 2018.

HERMES, Felippe. Os dez maiores casos de corrupção na história do Brasil. Disponível em: https://bit.ly/383mhUv. Acesso em 27 de janeiro de 2020.

JUSTEN FILHO, Marçal. Direito Administrativo do espetáculo. In: ARAGÃO, Alexandre Santos de; NETO MARQUES, Floriano de Azevedo. Direito Administrativo e seus novos paradigmas. Belo Horizonte: Fórum, 2017.

KHVALEI, Vladimir. Using Red Flags to Prevent Arbitration from Becoming a Safe Harbour for Contracts that Disguise Corruption. ICC International Court of Arbitration Bulletin v. 24, 2013.

KHVALEI, Vladimir. Using Red Flags to Prevent Arbitration from Becoming a Safe Harbour for Contracts that Disguise Corruption. ICC International Court of Arbitration Bulletin v. 24, 2013. 
Ministro Paulo Guedes em Davos: O combate à corrupção. Crítica Nacional Notícias. Disponível em: https://noticias.criticanacional.com.br/2020/01 /22/paulo-guedes-em-davos-o-combate-acorrupcao/. Acesso em 30 de janeiro de 2020

MOURRE, Alexis; Arbitration and Criminal Law: Reflections on the Duties of the Arbitrator. Oxford: Arbitration International. v. 22, 2006.

NALINI, José Renato. É urgente construir alternativas à justiça. in ZANETI JR, Hermes; CABRAL, Trícia Navarro Xavier. Justiça Multiportas: mediação, conciliação, arbitragem e outros meios de solução adequada para conflitos. Salvador: Juspodivm, 2016.

NIETO, Alejandro. El desgobierno de lo público. 2 ed. Barcelona: Ariel, 2013.

PARODI, Lorenzo. Manual das Fraudes. Rio de Janeiro: Brasport, 2005

PEREIRA, Cesar. Corrupção e arbitragem: os árbitros diante da alegação ou constatação de práticas ilícitas pelas partes. Disponível em http://justen.com.br/pdfs/IE138/IE138-Cesarcorrupcao-e-arbitragem.pdf. Acesso em 04 de abril de 2019.

PUENTES, Marcos Gómez. La Inactividade de la Administración. 3 ed. Navarra: Editorial Aranzadi, 2002.

RANZOLIN, Ricardo. Dever de Sigilo do Advogado Quando Atua Como Árbitro no Direito Brasileiro. Revista de Arbitragem e Mediação n. 53. São Paulo: Editora Revista dos Tribunais. 2017.

RAOUD, Mohamed Abdel . How Should Internacional Arbitrors Tackle Corruption Issuees. Foreign Investment Law Jornal. v. 24. Internacional Centre of Dispute Settlement of Investment Disputes, 2009.

RODAS, Sérgio. Árbitro não deve denunciar corrupção a autoridades, diz advogado dos EUA. CONJUR. Disponível em: https://bit.ly/3831zGP. Acesso em 20 de maio de 2019

ROSE-ARCKEMAN, Susan; PALIFKA Bonnie J. Corrupción y gobierno Causas, consecuencias y reformas. Madrid, Barcelona, Buenos Aires, São Paulo: Marcial Pons, 2019, p.125-157.

TRANSPARÊNCIA INTERNACIONAL. Brasil. Índice de percepção da corrupção. 2019. Disponível em https://ipc.transparenciainternacional.org.br/. Acesso m 28 de janeiro de 2020.

TRANSLEX. Disponível em https://www.trans-lex.org/201110 Acesso em 29 de sembro de 2020

VERÇOSA, Fabiane; MONEGALHA, Guilherme. Como deve se comportar o árbitro diante de indícios e provas de corrupção? Algumas impressões. Revista de Arbitragem e Mediação, v. 63, 2019.

VIVIANI, Luis. Brasil é o $5^{\circ}$ país que mais utiliza arbitragem no mundo. JOTA. Disponível em: https://bit.ly/2I1tXft. Acesso em 20 de janeiro de 2020. 
World Duty Free Company. República do Quênia, processo ICSID no Arb / 00/7. Disponível em https://www.italaw.com/cases/3280. Acesso em 10 de maio de 2019.

ZIMMER JÚNIOR, Aloísio. Corrupção e improbidade administrativa. São Paulo: Thomson Reuters Brasil, 2018. 